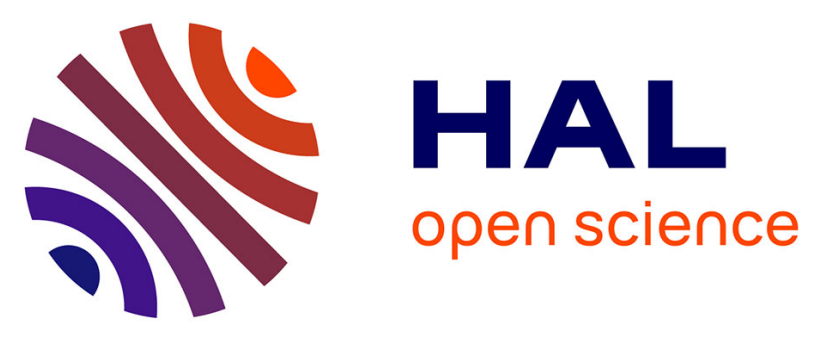

\title{
Comparison of the Screening Practices of Unaffected Noncarriers under 40 and between 40 and 49 in BRCA1/2 Families
}

\author{
Christelle Duprez, Veronique Christophe, Isabelle Milhabet, Aurélie
}

Krzeminski, Claude Adenis, Pascaline Berthet, Jean-Philippe Peyrat, Philippe

Vennin

\section{To cite this version:}

Christelle Duprez, Veronique Christophe, Isabelle Milhabet, Aurélie Krzeminski, Claude Adenis, et al.. Comparison of the Screening Practices of Unaffected Noncarriers under 40 and between 40 and 49 in BRCA1/2 Families. Journal of Genetic Counseling, 2013, 22 (4), pp.469-481. 10.1007/s10897012-9569-8 . hal-03109523

\section{HAL Id: hal-03109523 \\ https://hal.univ-lille.fr/hal-03109523}

Submitted on 13 Jan 2021

HAL is a multi-disciplinary open access archive for the deposit and dissemination of scientific research documents, whether they are published or not. The documents may come from teaching and research institutions in France or abroad, or from public or private research centers.
L'archive ouverte pluridisciplinaire HAL, est destinée au dépôt et à la diffusion de documents scientifiques de niveau recherche, publiés ou non, émanant des établissements d'enseignement et de recherche français ou étrangers, des laboratoires publics ou privés. 
Running head: unaffected noncarrier women and overscreening

Title

Comparison of the screening practices of unaffected noncarriers under 40 and between 40 and 49 in BRCA1/2 families

\section{Authors :}

Christelle Duprez ${ }^{1}$, Véronique Christophe ${ }^{1}$, Isabelle Milhabet ${ }^{2}$, Aurélie Krzeminski ${ }^{2}$, Claude Adenis $^{3}$, Pascaline Berthet ${ }^{4}$, Jean-Philippe Peyrat ${ }^{5}, \&$ Philippe Vennin $^{3}$

\section{Contact information and affiliations.}

1. URECA EA 1059, Université Lille Nord de France, Université de Lille 3, Villeneuve d'Ascq (France)

2. LAPCOS EA, Université de Nice-Sophia Antipolis, Nice (France)

3. Département de Sénologie, Centre Oscar Lambret, Lille (France)

4. Equipe multidisciplinaire d'oncogénétique, Centre François Baclesse, Caen (France)

5. Laboratoire d'Oncologie Moléculaire Humaine, Centre Oscar Lambret, Lille (France)

\section{Corresponding authors:}

Christelle DUPREZ, Temporary Lecturer and Research Assistant, Doctoral Student

Université de Lille 3

URECA EA 1059

Domaine Universitaire du pont de Bois

B.P. 60149

59653 Villeneuve d'Ascq cedex (France)

Tél. : 0320416706 / Fax : 0320416032 /Email. christelle.duprez@univ-lille3.fr

Véronique CHRISTOPHE, Professor

Université de Lille 3

URECA EA 1059

Domaine Universitaire du pont de Bois

B.P. 60149

59653 Villeneuve d'Ascq cedex (France)

Tél. : 0320416706 / Fax : 0320416032 / Email. veronique.christophe@ univ-lille3.fr 


\begin{abstract}
This study aimed to 1) compare the cancer screening practices of unaffected noncarrier women under 40 and those aged 40 to 49 , following the age-based medical screening guidelines, and 2) consider the way the patients justified their practices of screening or overscreening. For this study, 131 unaffected noncarriers - 77 women under age 40 and 54 between 40 and 49, all belonging to a BRCA1/2 family-responded to a questionnaire on breast or ovarian cancer screenings they had undergone since receiving their negative genetic test results, their motives for seeking these screenings, and their intentions to pursue these screenings in the future. Unaffected noncarriers under age 40 admitted practices that could be qualified as over-screening. Apart from mammogram and breast ultrasounds, which the women under 40 reported seeking less often, these women's screening practices were comparable to those of women between 40 and 49. Cancer prevention and a family history of cancer were the two most frequently cited justifications for pursuing these screenings. We suggest that health care professionals discuss with women under 50 the ineffectiveness of breast and ovarian cancer screenings so that they will adapt their practices to conform to medical guidelines and limit their exposure to the potentially negative impacts of early cancer screening.
\end{abstract}

Keywords: screening practices, over-screening practices, HBOC, asymptomatic, noncarriers, women under age 50. 
Comparison of the screening practices of unaffected noncarriers under 40 and between 40 and 49 in BRCA1/2 families

\section{Introduction}

Studies have determined that $5 \%$ to $10 \%$ of breast and ovarian cancers are hereditary and are linked to the transmission across generations of a mutation on the BRCA 1 and BRCA 2 genes (Risch et al. 2001). Women who do not have breast or ovarian cancer but who carry the mutation on one of those genes have a $50 \%$ to $85 \%$ lifetime risk of developing breast cancer and a $10 \%$ to $65 \%$ risk of developing ovarian cancer, compared with risks of approximately $10 \%$ and $1 \%$ among the general population, respectively (Antoniou et al. 2003; Chen et al. 2006; Risch et al. 2006). Women who already have breast or ovarian cancer and who carry the mutation have an increased risk of developing breast cancer in the other breast or of developing ovarian cancer (Metcalfe et al. 2004; Rogozinska-Szczepka et al. 2004). However, unaffected women belonging to a BRCA1/2 family but not carrying the mutation themselves have the same risks for developing breast or ovarian cancer as women in the general population (Domchek et al. 2010; Harvey et al. 2011; Korde et al. 2011).

While prevention is a major public health concern, screening can sometimes become problematic. For the last decade, a number of studies have been devoted to examining breast and ovarian cancer screening practices among women belonging to a BRCA1/2 family (McInerney-Leo et al. 2006; O'Neill et al. 2010). Whereas carriers followed the guidelines based on the results of their genetic tests, noncarriers seemed to adopt practices that were not recommended during the consultation discussing their test results. These women's screening practices can be problematic when they ignore the medical guidelines based on their age and personal or family history; unaffected women who belong to BRCA1/2 families but who 
receive negative results from their genetic test should not seek more cancer screening than women in the general population (Domchek et al. 2010; US Preventive Services Task Force 2009).

In France, the national breast cancer screening program, implemented since 2004, offers women from 50 to 74 years of age a bilateral mammogram every two years, with an agreement that the national health insurance will bear the medical costs (Institut National du Cancer 2010). This service is based on guidelines from the Haute Autorité de Santé established following the study of meta-analyses conducted on different age groups by a group of experts from several disciplines associated with breast cancer screening (Agence Nationale d'Accréditation et d'Evaluation en Santé 2004; Haute Autorité de Santé 2012). For women under age 40, no recommendation concerning screening is made; these women seek screening primarily for personal reasons. Although the recommendations seem clear for women under 40 or above 50, the medical and scientific community is still debating practices for women between 40 and 49 (e.g., Hendrick and Helvie 2011; Kopans 2010; Qaseem et al. 2007). This debate makes it difficult to determine what constitutes "over-screening" in this age group (Fletcher and Elmore 2003; Kadaoui et al. 2012; Nelson et al. 2009; US Preventive Services Task Force 2009). Several authors insist that screening under the age of 50 is a personal decision and that each woman should be informed of the advantages and disadvantages of screening, most notably the risk of false positives and the inadequate capacity to detect possible tumors in this age group (Institut National du Cancer 2010, 2012; Kearney and Murray 2009; National Institute of Health 1997; Smith 2000; Yokoe et al. 1998). Concerning breast self-examination (BSE) and clinical breast examination (CBE), there is still a debate. Although there is no French recommendation for or against these exams in the frame of individualized screening (Institut National du Cancer 2012), some AngloSaxon studies show that BSE does not reduce mortality and may increase benign biopsy rates 
(e.g., Mc Cready et al. 2005; Perry 2009; Rosolowich 2006). As a result, these studies view breast self-examination as an exam that may do more harm than good, and recommend that it should not be routinely taught to women, and that the benefits and risks of practicing this exam should be fully discussed with women who still request it. On the contrary, other studies (e.g., Fancher et al. 2011; Ma et al. 2012) criticize the recommendation made by the American Cancer Society. They argue that BSE should be optional, because this exam permits the detection of breast cancer, especially in young women who do not benefit from other exams such as mammograms. Even if women of 40 years old or under account for less than 5\% of women developing breast cancer (National Cancer Institute 2008), their cancers are more aggressive and have the highest likelihood of being palpable disease. It seems that a significant number of breast cancers are detected by this exam in women younger than 40 (Fancher et al. 2012; Ma et al. 2012). According to these Anglo-Saxon clinical studies, BSE should remain important for breast cancer diagnosis. CBE also can detect cancers missed by mammograms, but its role in cancer screening remains controversial (Chiarelli et al. 2009; Ma et al. 2012; Mc Donald et al. 2004).

This debate concerning the benefits and harms of breast cancer screening is in part due to the risk of overdiagnosis or overdetection, which occurs in cancers detected at screening that would not have otherwise become apparent in the woman's lifetime (Independent UK Panel on Breast Cancer Screening 2012). A recent literature review on European breast cancer screening by mammograms (Hofvind et al. 2012) concludes that the estimated risk of a falsepositive result in women aged 50-69 undergoing 10 biannual mammograms over a twodecade period vary from $8 \%$ to $21 \%$ in Europe (average $20 \%$ ), and that the risk of an invasive procedure (such as needle biopsy or surgical intervention) ranged from $1.8 \%$ to $6.3 \%$. Several reviews conclude that false-positive screening increases breast cancer anxiety and distress (Brewer et al. 2007; Saltz et al. 2010). However, even if the risk of over-diagnosis is real and 
may lead to an increased anxiety in women, the benefits of breast cancer screening appear to be higher than harms for women aged 50 or more (Independent UK Panel on Breast Cancer Screening 2012; Institut National du Cancer 2012).

Despite these recommendations, the results of recent epidemiological studies (Dawson et al. 2008; Dorval et al. 2011; Foster et al. 2007; Julian-Reynier et al. 2011; Peshkin et al. 2002) show that unaffected noncarriers belonging to a BRCA1/2 family admit to seeking screening that exceeds the medical guidelines and that would be qualified as "over-screening" by some of these authors (Dawson et al. 2008; Dorval et al. 2011). According to Dawson et al. (2008), most notably, for women under age 40, engaging in any one of the following screenings is sufficient to constitute over-screening: mammogram, clinical breast examination more than once a year, ovarian or breast ultrasound, breast self-examination or CA-125 testing. These data are summarized in Table 1.

\section{Insert here Table 1}

The explanations women give to justify their practices are, to our knowledge, rarely taken into account in the literature. Aro et al. (2001), for instance, considered data centered on women's reasons not to pursue screening. However, understanding the reasons that some women engage in over-screening might be helpful for developing interventions aiming at reducing the potentially deleterious consequences of excessive screening, including anxiety generated by false positives and the potential health hazards of repeated exposure to radiation from mammograms (Nekolla et al. 2008).

Purpose of the Present Study

The primary objective of this study is to estimate the screening, and possible over-screening, practices adopted by French women who are unaffected with cancer and noncarriers of a 
familial BRCA mutation; more precisely, the objective is to compare the screening practices of women under 40 with those of women between 40 and 49 . The secondary objective is to examine and better understand the reasons women themselves give for their screening and over-screening practices.

\section{Method}

\section{Participants}

The study participants consisted of 83 unaffected noncarriers under age 40, and 57 between 40 and 49 , who belonged to a BRCA1/2 family. These participants were seen in oncogenetic consultation between June 1997 and May 2009 in two cancer treatment and research centers in the northwest of France and agreed to take part in this study. The data on six participants under 40 and three participants between 40 and 49 were not used because of insufficiently completed questionnaires.

For the final statistical analysis, we selected the responses of 77 unaffected noncarrier women between 19 and $39(\mathrm{M}=32.09, \mathrm{SD}=5.21)$ who, on average, had received their test results nearly three years before the beginning of the study $(M=2.82, S D=1.78)$, and 54 women between 40 and $49(\mathrm{M}=44.89, \mathrm{SD}=2.49)$ who had received their test results nearly five years before the beginning of the study $(M=4.67, S D=2.73)$. Their socio-demographic characteristics and family backgrounds are shown in Tables 2 and 3.

Insert Tables $2 \& 3$

\section{Procedure}

After agreeing to participate, all participants who had been informed of their negative results at least one year before the beginning of the study received a letter by mail at their homes stating that they had been selected to take part in a study focusing on the personal 
experiences of women who had received genetic screening for breast and/or ovarian cancer. The women were assured that they were free to accept or refuse to participate and were guaranteed that their answers would remain anonymous and confidential. This informational letter was sent with a questionnaire and an agreement form that the participants were invited to fill in and return, via postage-paid envelope, to the research unit that had initiated the project. In addition, for each participant, a study research engineer prepared a medical card detailing the number of the participant's relatives with breast, ovarian or another type of cancer; the number of relatives who had died as a result of the disease, and the respondent's possible recourse to prophylactic surgery. This study obtained all required legal and ethical authorizations (Comité de Protection des Personnes; Comité Consultatif sur le Traitement de l'Information en matière de Recherche dans le domaine de la Santé; Commission Nationale de l'Informatique et des Libertés).

\section{Measures}

The primary dependent variable, which was derived from self-reported responses to a questionnaire, was the respondents' screening practices since receiving the results of their gene tests. The respondents' self-reported practices were considered to be "over-screening" if they consisted of more screening than the medical community recommends. For comparison, the six screening practices listed on our questionnaire were similar to those discussed in the reference literature (i.e., Dawson et al. 2008): mammogram before the age of 40, clinical breast examination more than once a year, ovarian ultrasound, breast ultrasound, breast selfexamination and CA-125 testing. In addition to socio-demographic and medical data, the questionnaire elicited 1) participants' reasons for their chosen screening practices, and 2) their intentions to continue these screening practices in the future. 
Screening practices. Each participant was asked whether, since receiving the results of her gene test, she had pursued any of the following screenings: mammogram, breast selfexamination, clinical breast examination by a doctor, breast ultrasound, ovarian ultrasound, or CA-125 testing. If the response to any of these was yes, the next question asked was how often: less than once a year, once a year, twice a year, more often. This evaluated frequency permitted us to determine if there was over-screening or not for the clinical breast examination. Indeed, contrary to the other screening practices evaluated, whose mere presence was considered as over-screening, the clinical breast examination was not considered as over-screening per se, but only if received more than once a year. On this basis, an over-screening score was calculated for each participant by summing the number of screenings each woman had self-reported seeking or engaging in (ranging from $0=$ received no screenings to $6=$ received all six of the screenings listed). For women under age 40 , a score of 1 was sufficient to be considered over-screening. For women over 40, we do not use the term "over-screening," due to the fact that recommendations are less clear for these women. Consequently, the score is an indicator of their screening practices.

Motives for seeking screening. Participants were invited to provide the precise reasons they had sought these screenings in the form of a free response question (i.e., What are the reasons that encouraged you to get tested?).

Intentions. Participants were asked (yes or no) if they had considered modifying their screening practices in the future; if they reported that they did intend to change their practices, they were asked what change they intended to make (reducing or increasing frequency). In a free response question, participants were also asked why they were or were not considering making changes in these practices.

\section{Data analysis}


The data concerning the screening practices were first subjected to a descriptive analysis detailing the presence and the frequency of each of the screening practices. The screening practices of the participants under 40 were then compared with those of the participants between 40 and 49 using chi-square tests. A Mann Whitney U test was used to evaluate the impact of age group on the over-screening score.

Two independent judges conducted a content analysis (Bardin 1991) of the reasons participants gave for their screening practices $(n=49$ women under $40, n=46$ women between 40 and 49), and of the reasons they gave for modifying their intended future screening practices. When the number of participants was sufficient, chi-square tests were used to compare the proportions of the different reasons reported by the two age groups.

\section{Results}

\section{Characteristics of the participants}

As shown in Table 2, a majority of women had a higher education diploma (over three fourths for the women under 40, and over one-half for the women aged 40-49), and worked in Administrative, Sales or Service Occupations (40\% of the women under $40,43 \%$ of the women aged 40-49 years). Concerning their marital status, the majority of women was in a relationship (nearly $80 \%$ of the women, whatever their age) and had children (nearly $69 \%$ for the women under 40 , and $92 \%$ for the women over 40 ).

Concerning their family history, not surprisingly most women had at least one first-degree relative affected (nearly $69 \%$ of the women under 40 , and $63 \%$ of the women over 40 ) by breast and/or ovarian cancer or deceased by this cancer (nearly $25 \%$ of the participants under $40,33 \%$ of the women over 40 ). Whatever their age, most participants also had another 
degree relatives affected or deceased by breast and/or ovarian cancer, or by another type of cancer (Table 3).

\section{Breast and ovarian cancer screening practices}

On the whole, a large number of the unaffected noncarriers in both age groups, pursued breast and ovarian cancer screenings in the years after receiving their gene test results (Table 4). According to the previously defined criteria, these practices nearly always constituted over-screening for the women in both age groups (Table 5). More precisely, $23.4 \%$ of the 77 women under 40 self-reported over-screening by mammograms, $13 \%$ by clinical breast examination (i.e., having this exam more than once a year), $42.9 \%$ by breast self-examination, $19.5 \%$ by breast ultrasound, and $24.7 \%$ by ovarian ultrasound (Tables $4 \&$ 5). However, none of these young unaffected noncarriers reported CA-125 testing. For women over 40, the term "over-screening" could not be used, due to the fact that recommendations are less clear for these women. More than $80 \%$ of the 54 women from this age group self-reported having at least a mammogram since their gene test result; $11.1 \%$ had clinical breast examination more than once a year. Half of these women over 40 used breast self-examination, and nearly $52 \%$ of them self-reported breast ultrasound. Last, $22 \%$ of these women had ovarian ultrasound.

Insert Tables 4 \& 5

We observed that the women between 40 and 49 on the whole self-reported more over-screening practices than did the women under 40 (i.e., mammogram before the age of 40, clinical breast examination more than once a year, ovarian ultrasound, breast ultrasound, breast self-examination and CA-125 testing; sum of over-screening scores for women 40 to $49=4437$ versus 4208 for women under 40; Mann-Whitney $\mathrm{U}=1205.5, p<.05$ ). These 
results primarily were derived from the increased numbers of mammograms and breast ultrasounds these women received; the women in the age group of 40 to 49 more often reported having obtained a mammogram and/or a breast ultrasound since receiving their gene test results than did the women under 40 (Tables 4 and 5). Both age groups reported comparable practices concerning clinical breast examination more than once a year $(n=10$ for the women under 40 versus $n=6$ for the women aged 40 to $49, \chi^{2}(1)=.914$, ns). Moreover, the two age groups did not differ in their breast self-examination practices or in the frequency (once a year, twice a year) with which they administered this test (Tables 4 and 5). There was also no difference in having obtained an ovarian ultrasound after receiving the gene test results, and in addition, only one woman between 40 and 49 reported that she had received CA-125 testing once a year since receiving her test results (Tables 4 and 5).

\section{Screening motives}

As indicated in Table 6, the most prevalent reasons for seeking screening cited by participants, regardless of age, cited were the desire to detect and treat the disease in time (41\% of the women under 40 and $48 \%$ of the women over 40 self-reported this motive for screening) and family medical history (41\% of the women under $40,54 \%$ of the women over 40). The fear of cancer was also often mentioned by the women under $40(10 \%)$ as much as by the women between 40 and $49(23 \%)$. To explain their screening practices, 5 women under $40(10.20 \%)$ and 3 women between 40 and 49 (6.52\%) cited usual supervision (i.e., the fact that the screening practices were undertaken in the frame of their usual medical appointments).

Insert Table 6 


\section{Intention to modify screening practices}

As a complementary analysis, we explored participants' intentions of changing their screening practices. On the whole, the majority of the women $(83.2 \% ; 71.5 \%$ of those under 40 , and $80 \%$ of those between 40 and 49 ) reported they were not considering modifying their screening practices in the future. Among the 22 participants who were considering changing their practices, each indicated that she intended to increase the screenings evaluated in the study because the risk of cancer increases with age (Table 7).

\section{Insert table 7}

\section{Discussion}

Our primary objective was to determine whether French unaffected noncarriers adopt breast and/or ovarian cancer over-screening practices. Because of the ongoing debate among experts regarding appropriate screening guidelines for women between 40 and 49 (Fletcher and Elmore 2003; Hendrick and Helvie 2011; Kadaoui et al. 2012; Nelson et al. 2009; Qaseem et al. 2007), it was also necessary to compare the self-reported practices of the women of this age group with those reported by the women under 40 , for whom the screening guidelines are sufficiently clear (i.e., screening is not recommended and is a personal decision among this age group).

As expected, and in keeping with the literature, our results show the presence of earlier and/or more frequent screening practices (i.e., over-screening) among French unaffected noncarriers than are recommended by clinical guidelines. In particular, a large majority of noncarriers under age 40 reported having obtained a mammogram and/or a breast ultrasound since receiving their gene test results. Given that for women under 40, these two practices can be considered over-screening, it was reassuring that the data showed the women in this age 
group obtained those two screenings less frequently than did the women between 40 and 49 years of age. The fact that the majority of the women between 40 and 49 had received mammograms $(83 \%)$ or breast ultrasounds $(51 \%)$ during the years after receiving their test results may be attributable to the ongoing debate regarding appropriate screening recommendations for this age group; when screening was a personal decision rather than a recommendation, these women might have chosen early screening (before age 50) because of their family histories. This hypothesis is consistent with the reasons the women gave for seeking screening; for women in this age group, a family history of cancer was the primary motive for seeking screening.

In contrast, for the other screening practices we studied (i.e., clinical breast examination more than once a year, breast self-examination, ovarian screening ultrasound screening), self-reported practices were comparable in both age groups. These observations suggest that women under 40 pursue earlier and/or more frequent screenings than recommended based on their risk of cancer. These data also show that these women obtained these three screening tests in the same proportions as the women between 40 and 49 . Due to the fact the validity of these screenings is still being debated for women aged 40-49, these screenings may be more easily justified in this age group. This latter assessment is even more striking because the women between 40 and 49 had received their negative gene test results well before the beginning of the study (approximately 5 years before, versus 3 years for the participants under 40) and could therefore have reported pursuing more screening than the women under 40 .

The results of our study, with their specificities, are consistent with findings of the two recent francophone studies (Dorval et al. 2011; Julian-Reynier et al. 2011) and of the AngloSaxon studies conducted among unaffected noncarriers in BRCA1/2 families (Dawson et al. 2008; Foster et al. 2007; Peshkin et al. 2003). Indeed, the proportions of women in the present 
study who pursued screening are, on the whole, comparable with those of the women in other studies conducted on the screening practices of unaffected noncarriers (see Table 1). Among the women in our study under age 40 , over-screening by mammogram was undertaken in the same proportions as those reported by Foster et al. (2007). Similarly, the French participants in our sample underwent over-screening by ovarian ultrasound as often as the Anglo-Saxon women questioned by Dawson et al. (2008) and Dorval et al. (2011). Nevertheless, the women in our study under age 40 seemed to seek mammograms less often than the women in the Dawson et al. (2008) study, in which $36 \%$ between ages 30 and 39 reported having obtained a mammogram in the years following the announcement of their results. The present sample of women also differentiate themselves from the women questioned by Julian-Reynier et al. (2011), who found that 53\% of their sample between ages 30 and 39 had obtained a mammogram in the 5 years since receiving their gene test results. In the same way, the unaffected noncarriers in our study reported conducting breast self-examination less often than did the Anglo-Saxon participants in the same age group; only $42 \%$ of the women in our study had performed this screening compared to $68 \%$ of the respondents in Dawson et al. (2008) and $100 \%$ of those in Foster et al. (2007) study.

In contrast, the women in our study pursued breast ultrasounds more often than did the participants in the study by Julian-Reynier et al. (2011): $19 \%$ of our respondents under 40 reported having obtained this screening since receiving their gene test results, compared with only approximately 5\% in the study by Julian-Reynier et al. (2011). This result may be linked to the larger age range in our study: among our unaffected respondents under 40 , the youngest was 19 years old, whereas the youngest participant in the study by Julian-Reynier et al. (2011) was 30 years old. Similarly, more participants in our study $(21 \%)$ reported receiving clinical breast examinations more than once a year, compared with only $10 \%$ of the Anglo-Saxon women between 20 and 39 in Dawson et al. (2008). Finally, CA-125 testing was markedly 
less frequent for the participants in our study than for the Anglo-Saxon participants in Dawson et al. (2008), the only study examining the frequency of this screening.

In our study, the women between 40 and 49 obtained mammograms and clinical breast examinations in the same proportions as those reported by Dawson et al. (2008) and Dorval et al. (2011). In addition, at $41 \%$ and $22 \%$, respectively, the participants in Dorval et al. (2011) clearly obtained ovarian ultrasounds more often than did the women in our study. Similarly, the unaffected noncarriers between 40 and 49 in our study conducted breast self-examinations less often than the participants of the two other studies of this age bracket; $50 \%$ of our respondents reported having performed this screening in the years after receiving their gene test results, versus 63\% in Dawson et al. (2008), and 83\% in Dorval et al. (2011). Finally, similar to the women under 40 , our participants between 40 and 49 reported seeking CA-125 testing less often than did the Anglo-Saxon participants of Dawson et al. (2008).

It is striking to note that clinical breast examination was, along with breast selfexamination, the most frequent screening practice reported by the women under 40; nearly $60 \%$ of these participants reported performing this screening since receiving their test results. The most frequent screening practices among the women between 40 and 49 were mammogram, clinical breast examination, breast ultrasound, and breast self-examination. Although breast self-examination can be performed without medical instruction, the other screenings require a medical prescription. The results of our study thus draw attention to the possible difficulties of coordinating follow-up medical recommendations among practitioners who see young and unaffected noncarriers. There is evidence that general practitioners and gynecologists, being aware that these women belong to a family with hereditary cancer risk, overestimate their patients' risk of cancer and may prescribe these examinations "as a precaution" (Cockburn et al. 1989; Sabatino et al. 2007). 
In support of this hypothesis, several studies have shown that doctors are sometimes unaware of the guidelines concerning breast cancer screening. Gili et al. (1993) reported that nearly $85 \%$ of the general practitioners questioned for an investigation conducted in Canada were unaware of the national guidelines concerning breast cancer screening; thus, most of these practitioners advise women under 40, including teenagers, to conduct regular breast self-examination. The guidelines, however, suggest receiving a clinical examination once a year from the age of 40 on and not conducting breast self-examination. Despite these recommendations, $38 \%$ of Canadian general practitioners continue to instruct their patients under 40 in how to perform breast self-examination (Kadaoui et al. 2012). Regarding mammograms, 54\% of the 1212 American general practitioners questioned in a different study believed that the efficiency of this examination has been proven in women between 40 and 49 and therefore recommend it to their patients (Meissner et al. 2011). We find similar data in France in an investigation of the practices of 600 general practitioners; most of these practitioners $(60 \%)$ begin screening for breast cancer in women under 50 , that is, before the age recommended in the national screening plan (Enquête $\mathrm{INCa} / \mathrm{Bva} 2010$ ).

Therefore, there appears to be a gap between the screening guidelines promoted by health authorities -which differ based on country- and the recommendations that general practitioners make to their patients. This gap is problematic because recommendations by general practitioners tend to be strong predictors of women's future cancer screening practices (Friedman et al. 1995; Giveon and Kahan 2000; Tinley et al. 2004). The data from a recent national French investigation (Pivot et al. 2011), for instance, revealed that a woman's age and her visits to a general practitioner or a gynecologist during the year were predictors that women under 40 would seek mammograms.

In addition to examining the screening and over-screening practices of women under 40 and those between 40 and 49 and comparing those practices, this study also aimed to 
consider why women pursued certain screenings. Learning from the women themselves why they pursue over-screening for cancer is a useful complement to the data from previous studies on the screening practices of unaffected noncarrier women. In particular, knowing why women pursue screening can help in suggesting methods for reducing over-screening. Most of our participants, regardless of age, reported birth family history of cancer and the desire to detect and treat the disease in a timely manner as their primary motives for seeking screening. Among the 35 women who answered this question, most respondents, whatever their age group, also intended to increase their screening practices in the future because cancer risk increases with age, and fear of cancer was frequently reported by the women in both age groups. If we cannot rule out the possibility that the women who were most anxious about cancer were also the most likely to complete our questionnaire, we can hypothesize that these women have a deep anxiety about cancer in general and that this anxiety would be reinforced by the existence of a family history of breast or ovarian cancer. This anxiety might then lead these concerned women to ask their general practitioners for specific medical examinations, regardless of whether they belong to an age group for which screening is recommended. This hypothesis is supported by the results of recent studies finding that young, unaffected noncarriers overestimate their lifetime cancer risk and attempt to reduce these risks by engaging in early preventive practices (Hoskins et al. 2012; Milhabet et al. 2012; Pilarski 2009; Vos et al. 2012).

It is possible that unaffected noncarriers overscreen because belonging to a BRCA positive family led them to still believe they are at high risk of developing cancer, even if they do not carry the BRCA1/2 mutation. These women may still overestimate their risk for cancer because they have "always believed" they are at high risk. Due to the familial context, before entering into the genetic testing process, the majority of women from BRCA family think they carry the mutation (Caruso et al., 2009; Mc Inerney-Leo et al., 2006). This risk 
perception may lead them to undertake screening practices. Indeed, two meta-analyses (Katapodi et al.2004; McCaul et al.1996) showed that the perceived risk of breast cancer predicts the adoption of mammograms screening. These over-screening practices could also be attributed to media reports regarding medical examinations and prevention, which increase cancer awareness but can also increase anxiety. Practitioners might then seek to reassure their patients by prescribing medical screening examinations. Breast self-examination, for instance, which can be conducted without medical recommendations, is strongly publicized by the media and is even presented as an effective examination. Performing these examinations is represented as a way for these women to reassure themselves about their good health. It is also possible that performing such breast-self examinations may be a way to achieve control over an uncontrollable situation which generates anxiety (i.e., the fact of belonging to a BRCA family). Although they do not themselves carry the BRCA1/2 mutation, young unaffected noncarriers have a lot of relatives who carry this mutation and/or are affected or deceased by cancer. It may lead them to a sense of helplessness, and to a wish to recover control, by choosing to undertake screening "as a precaution" (Epstein et al. 1997; McCaul et al. 1996; Rosenstock 1990; Rowe et al., 2005). Moreover, it is possible that the perceptions women have of the "relevance" of these medical guidelines influence their over-screening practices. In a study of women's perceptions of mammograms (the usefulness of which among women between 40 and 49 is still debated among American health experts), $83 \%$ of the 503 participants indicated that they believe mammograms are beneficial for women between 40 and 49 (Woloshin et al. 2000). Moreover, 38\% of these women believed that mammograms are effective for women under 40, and most believed that screening should begin before the age of 40 . For the women who participated in the study by Woloshin et al. (2000), the current debate on mammogram recommendations is more about financial costs than about ineffectiveness or the possible dangers of repeated radiation exposure. 
Interestingly, only $52 \%$ of these women reported trusting the national screening recommendations (Woloshin et al. 2000). For more than half of the participants (61\%), their general practitioner is the primary source of information on mammograms, and their general practitioner is the prescribing physician in $57 \%$ of the cases. It is also notable that $23 \%$ of the respondents had asked their providers for a mammogram and only $20 \%$ had never discussed mammograms with their general practitioner (Woloshin et al. 2000). Similarly, only $15 \%$ of the Swiss women questioned by Chamot and Perneger (2002) were aware of the fact that mammograms are not recommended before the age of 50.

\section{Study limitations and research recommendations}

The primary limitation of this study is that screening and over-screening practices were estimated from self-reports; the participants completed self-administered questionnaires regarding their screening practices since receiving their gene test results. Given the amount of time that had passed between the participants' learning their test results and the beginning of our study (nearly 3 years for the participants under 40 and 5 years for those between 40 and 49) it is possible that their self-reported practices do not reflect their actual screening histories. Nevertheless, several studies (Barratt et al. 2000; Caplan et al. 2003) demonstrate the validity of self-reported practices concerning cancer screening. Caplan et al. (2003) found that participants' self-reported screening practices corresponded with the records of medical registers by $88.4 \%$ for mammograms, and by $87.4 \%$ for clinical self-examination. Moreover, if self-reported measures are indeed biased, the tendency is for women to underestimate the time elapsed since their last screening examination (Caplan et al. 2003). Our results are comparable with those of previous studies based on the same methodology (e.g., Dawson et al. 2008; Dorval et al. 2011). 
Another limitation to our study is the relatively small number of respondents, particularly between the ages of 40 and $49(n=54)$. This limitation appears to be linked to both the population studied and the methodology used; the number of women in our study is nearly identical to that in the previous studies (e.g., Julian-Reynier et al. 2011). To the extent that our study is, to our knowledge, the first to focus on the reasons that young, unaffected noncarriers give for over-screening, additional investigations are warranted to determine whether the results can be replicated with a larger sample of these same age groups. Another limitation could consist of the fact that the 40-49 years old women received their genetic test result on average 5 years prior to the study. Thus, many of them may have been aged under 40 when engaged in over-screening. Even if there are no statistical differences between them and the 40-49 years sample, a prospective study would be a better method to mitigate the consequences of this potential bias.

Although the present data confirm that young, unaffected noncarriers pursue overscreening, we cannot dismiss the hypothesis that these women sought screening less often after they received the results of their genetic testing. For some women, these practices would still be excessive compared with the clinical guidelines, but these less frequent screenings could indicate that the consultations accompanying the delivery of the test results had a positive impact on screening practices. In another study, even before their first oncogenetic consultation, half of the women aged 40 and 49 with a family history of breast and/or ovarian cancer reported having obtained a mammogram (Isaacs et al. 2002). Yet, insofar as past health behaviors are strong predictors of future health behaviors, it is possible that women belonging to BRCA1/2 families, regardless of their genetic test results, will not modify their screening practices (e.g., Lechner et al. 1997). It would therefore be interesting to test this hypothesis with a longitudinal study designed to increase understanding of how the screening practices of noncarriers evolve throughout the process of genetic testing. 


\section{Practical implications}

Given that medical examinations are ineffective at detecting possible tumors in young women and that they may actually contribute to anxiety because of the high rate of false positives (e.g., Lehman et al. 1999; for details, see Eisinger et al. 2004), the findings of this study have implications for clinical practice. The breast and ovarian cancer over-screening practices of young women suggest that these women, particularly those under 40 , would benefit from preventive communication focused on the ineffectiveness of such screenings for their age group. Such communication could encourage these women to keep their screening practices in line with medical guidelines and thus limit the possible negative effects of early screening practices. Following the example put forward by Dawson et al. (2008), providing follow-up care after the initial genetic test result consultations could ensure that noncarriers adhere to recommended screening practices. During the genetic counseling process, and even if they are not at risk of developing cancer to a greater extend that another woman, unaffected young noncarriers should be particularly attended to by genetic counselors. Indeed, it seems important to verify they really understand the implications of their genetic test result ( i.e., even if they belong to a BRCA1/2 family, their personal risk for developing breast or ovarian cancer is similar to that of a woman who does not belong to such a family). Due to their probably biased risk perception, it seems important that during genetic counseling, the potential fears of unaffected noncarriers are fully discussed, in order to reassure them and to avoid their using over-screening practices. In addition to ensuring that noncarriers clearly understand the implications of their test results for medical follow-up, and considering the data from the various studies presented, it is also important to ensure that health care professionals accurately present these patients' cancer risks based on their noncarrier status and that they adapt their recommendations to their patients' genetic status. 


\section{Acknowledgements}

The authors thank the Fondation de France for financing the project, as well as the oncogenetic consultations of the Centre Oscar Lambret and of the Centre François Baclesse for their most valuable help in data-gathering. A big thanks also to the participants who agreed to take part in the study. 


\section{REFERENCES}

Agence Nationale d'Accréditation et d'Evaluation en Santé (2004). Opportunité d'étendre le programme national de dépistage du cancer du sein aux femmes âgées de 40 à 49 ans: actualisation mars 2004. http://www.has-sante.fr/portail/jcms/c_464090/opportunitedetendre-le-programme-national-de-depistage-du-cancer-du-sein-aux-femmes-agees-de40-a-49-ans?xtmc=\&xtcr=20. Accessed 29 february 2012.

Antoniou, A., Pharoah, P. D., Narod, S., Risch, H. A., Eyford, J.E., Hoppe, J. L., et al. (2003). Average risks of breast and ovarian cancer associated with BRCA1 or BRCA2 mutations detected in case series unselected for family history: A combined analysis of 22 studies. American Journal of Human Genetics, 72(5), 1117-1130.

Aro, A. R., de Koning, H. J., Absetz, P., \& Schreck, M. (2001). Two distinct groups of nonattenders in an organized mammography screening program. Breast Cancer Research and Treatment, 70(2), 145-153.

Bardin, L. (1991). L'analyse de contenu. Paris: Presses Universitaires de France.

Barratt, A., Cockburn, J., Smith, D., \& Redman, S. (2000). Reliability and validity of women's recall of mammographic screening. Australian and New Zealand Journal of Public Health, 24(1), 79-81.

Brewer, N.T., Salz, T., \& Lillie, S.E. (2007). Systematic review: The long-term effects of false-positive mammograms. Annals of Internal Medicine, 146, 502-510.

Caplan, L. S., McQueen, D.V., Qualters, J. R., Leff, M., Garrett, C., \& Calonge, N. (2003). Validity of women's self-reports of cancer screening test utilization in a managed care population. Cancer Epidemioly, Biomarkers \& Prevention, 12 (11 Pt 1), 1182-1187.

Caruso, A., Vigna, C., Marozzo, B., Sega, F. M., Sperduti, I., Cognetti, F., \& Savarese, A. (2009). Subjective versus objective risk in genetic counseling for hereditary breast and/or ovarian cancers. Journal of experimental \& clinical cancer research, 28, 157.

Chamot, E., \& Perneger, T. V. (2002). Men's and women's knowledge and perceptions of breast cancer and mammography screening. Preventive Medicine, 34, 380-385. 
Chen, S., Iversen, E. S., Friebel, T., Finkelstein, D., Weber, B. L., Eisen, A., et al. (2006). Characterization of BRCA1 and BRCA2 mutations in a large United States sample. Journal of Clinical Oncology, 24(6), 863-871.

Chiarelli, A. M., Majpruz, V., Brown, P., Thériault, M., Shumak, R., \& Mai, V. (2009). The contribution of clinical breast examination to the accuracy of breast screening. Journal of the National Cancer Institute, 101(18), 1236-1243.

Cockburn, J., Irwig, L., Turnbull, D., Simpson, J. M., Mock, P., \& Tattersall, M. (1989). Encouraging attendance at screening mammography: knowledge, attitudes and intentions of general practitioners. Medical Journal of Australia, 151(7), 391-396.

Dawson, S. J., Price, M. A., Jenkins, M. A., McKinley, J. M., Butow, P. N., McLachlan, S. A., et al. (2008). Cancer risk management practices of noncarriers within BRCA1/2 mutation-positive families in the Kathleen Cuningham Foundation Consortium for research into familial breast cancer. Journal of Clinical Oncology, 26(2), 225-232.

Domchek, S. M., Gaudet, M. M., Stopfer, J. E., Fleischaut, M. H., Powers, J., Kauff, N., et al. (2010). Breast cancer risks in individuals testing negative for a known family mutation in BRCA1 or BRCA2. Breast Cancer Research and Treatment, 119(2), 409-414.

Dorval, M., Nogues, C., Berthet, P., Chiquette, J., Gauthier-Villars, M., Lasset, C., et al. (2011). Breast and ovarian cancer screening of non-carriers from BRCA1/2 mutationpositive families: 2-year follow-up of cohorts from France and Quebec. European Journal of Human Genetics, 19(5), 494-499.

Eisinger, F., Bressac, B., Castaigne, D., Collu, P. H., Lansac J., Lefranc, J. P., et al. (2004). Identification et prise en charge des prédispositions héréditaires aux cancers du sein et de l'ovaire (mise à jour 2004). Bulletin du Cancer, 91(3), 219-237.

Enquête INCa / BVA (2010). Médecins généralistes et dépistage des cancers. www.ecancer.fr Accessed 29 February 2012.

Epstein, S. A., Lin, T. H., Audrain, J., Stefanek, M., Rimer, B., \& Lerman, C. (1997). Excessive breast self-examination among first-degree relatives of newly diagnosed breast cancer patients. High-Risk Breast Cancer Consortium. Psychosomatics, 38(3), $253-261$. 
Fancher, T. T., Palesty, J. A., Paszkowiak, J. J., Kiran, R. P., Malkan, A. D., \& Dudrick, S. J. (2011). Can breast self-examination continue to be touted justifiably as an optional practice? International journal of surgical oncology, doi:10.1155/2011/965464.

Fletcher, S. W., \& Elmore, J. G. (2003). Clinical practice. Mammographic screening for breast cancer. New England Journal of Medicine, 348(17), 1672-1680.

Foster, C., Watson, M., Eeles, R., Eccles, D., Ashley, S., Davidson, R., et al. (2007). Predictive genetic testing for BRCA1/2 in a UK clinical cohort: Three year follow-up. British Journal of Cancer, 96(5), 718-724.

Friedman, L. C., Woodruff, A., Lane, M., Weinberg, A. D., Cooper, H. P., \& Webb, J. A. (1995). Breast cancer screening behaviors and intentions among asymptomatic women 50 years of age and older. American Journal of Preventive Medicine, 11(4), 218-223.

Gili, A. F., Poonja, Z., \& Kalra, B. B. (1993). Breast cancer screening for women younger than 40. Canadian Family Physician, 39, 65-72.

Giveon, S., \& Kahan, E. (2000). Patient adherence to family practitioners' recommendations for breast cancer screening: a historical cohort study. Family Practice, 17(1), 42-45.

Harvey, S. L., Milne, R. L., McLachlan, S. A., Friedlander, M. L., Birch, K. E., Weideman, P., et al. (2011). Prospective study of breast cancer risk for mutation negative women from BRCA1 or BRCA2 mutation positive families. Breast Cancer Research and Treatment, 130, 1057-1061.

Haute Autorité de Santé (2012). Participation au dépistage du cancer du sein : Recommandations de la HAS pour les femmes de 50 à 74 ans. http://www.hassante.fr/portail/jcms/c_1196105/cancer-du-sein-un-nouveau-souffle-pour-le-depistageorganise. Accessed 29 february 2012

Hendrick, R. E.., \& Helvie, M. A. (2011). United States Preventive Services Task Force screening mammography recommendations science ignored. American Journal of Roentgenoly, 196, W-236.

Hofvind, S., Ponti, A., Patnick, J., Ascunce, N., Njor, S., Broeders, M., Van Hal, G. (2012). False-positive results in mammographic screening for breast cancer in Europe: a 
literature review and survey of service screening programmes. Journal of medical screening, 19 Suppl 1, 57-66.

Hoskins, L.M., Roy, K.M., \& Greene, M.H. (2012). Toward a new understanding of risk perception among young female BRCA1/2 “previvors". Families, Systems, \& Health, $30(1), 32-46$.

Independent UK Panel on Breast Cancer Screening (2012). The benefits and harms of breast cancer screening: an independent review. Lancet, 380(9855), 1778-1786.

Institut National du Cancer (2010). Les recommandations en matière de dépistage des cancers : propositions pour un nouveau modèle. http://www.e-cancer.fr/toutes-lesactualites/235/4548-les-recommandations-en-matiere-de-depistage-des-cancerspropositions-pour-un-nouveau-modele. Accessed 29 february 2012

Institut National du Cancer (2012). Dépistage du cancer du sein : qui est concerné? http://www.e-cancer.fr/depistage/depistage-du-cancer-du-sein/espace-grand-public/quiest-concerne-. Accessed 21 november 2012

Institut National du Cancer (2012). Limites et incertitudes sur le dépistage. http://www.ecancer.fr/depistage/depistage-du-cancer-du-sein/limites-et-incertitudes-sur-le-depistage. Accessed 21 november 2012

Isaacs, C., Peshkin, B. N., Schwartz, M., Demarco, T. A., Main, D., \& Lerman, C. (2002). Breast and ovarian cancer screening practices in healthy women with a strong family history of breast or ovarian cancer. Breast Cancer Research and Treatment, 71(2), 103112.

Julian-Reynier, C., Mancini, J., Mouret-Fourme, E., Gauthier-Villars, M., Bonadona, V., Berthet, P., et al. (2011). Cancer risk management strategies and perceptions of unaffected women 5 years after predictive genetic testing for BRCA1/2 mutations. European Journal of Human Genetics, 19(5), 500-506.

Kadaoui, N., Guay, M., Baron, G., St-Cerny, J., \& Lemaire, J. (2012). Breast cancer screening practices for women aged 35 to 49 and 70 and older. Canadian Family Physician, 58, 47-53. 
Katapodi, M. C., Lee, K. A., Facione, N. C., \& Dodd, M. J. (2004). Predictors of perceived breast cancer risk and the relation between perceived risk and breast cancer screening: a meta-analytic review. Preventive medicine, 38(4), 388-402.

Kearney, A. J., \& Murray, M. (2009). Breast cancer screening recommendations: is mammography the only answer? Journal of midwifery \& women's health, 54(5), 393-400.

Kopans, D. B. (2010). The 2009 US Preventive Services Task Force (USPSTF) guidelines are not supported by science: the scientific support for mammography screening. Radiologic clinics of North America, 48(5), 843-857.

Korde, L. A., Mueller, C. M., Loud, J. T., Struewing, J. P., Nichols, K., Greene, M. H., et al. (2011). No evidence of excess breast cancer risk among mutation-negative women from BRCA mutation-positive families. Breast Cancer Research and Treatment, 125, 169173.

Lechner, L., de Vries, H., \& Offermans, N. (1997). Participation in a breast cancer screening program: influence of past behavior and determinants on future screening participation. Preventive Medicine, 26(4), 473-482.

Lehman, C. D., White, E., Peacock, S., Drucker, M. J., \& Urban, N. (1999). Effect of age and breast density on screening mammograms with false-positive findings. American Journal of Roentgenology, 173(6), 1651-1655.

Ma, I., Dueck, A., Gray, R., Wasif, N., Giurescu, M., Lorans, R., Pockaj, B. (2012). Clinical and self breast examination remain important in the era of modern screening. Annals of surgical oncology, 19(5), 1484-1490.

McCaul, K. D., Branstetter, A. D., Schroeder, D. M., \& Glasgow, R. E. (1996). What is the relationship between breast cancer risk and mammography screening? A meta-analytic review. Health psychology: official journal of the Division of Health Psychology, 15(6), 423-429.

McCready, T., Littlewood, D., \& Jenkinson, J. (2005). Breast self-examination and breast awareness: a literature review. Journal of clinical nursing, 14(5), 570-578. 
McDonald, S., Saslow, D., \& Alciati, M. H. (2004). Performance and reporting of clinical breast examination: a review of the literature. CA: a cancer journal for clinicians, 54(6), 345-361.

McInerney-Leo, A., Hadley, D., Kase, R. G., Giambarresi, T. R., Struewing, J. P., \& Biesecker, B. B. (2006). BRCA1/2 testing in hereditary breast and ovarian cancer families III: Risk perception and screening. American Journal of Medical Genetics $140 A, 2198-2206$.

Meissner, H. I., Klabunde, C. N., Han, P. K., Benard, V. B., \& Breen, N. (2011). Breast cancer screening beliefs, recommendations and practices: primary care physicians in the United States. Cancer, 117(14), 3101-3111.

Metcalfe, K., Lynch, H. T., Ghadirian, P., Tung, N., Olivotto, I., Warner, E., et al. (2004). Contralateral breast cancer in BRCA1 and BRCA2 mutation carriers. Journal of Clinical Oncology, 22(12), 2328-2335.

Milhabet, I., Duprez, C., Krzeminski, A., \& Christophe, V. (2012). Cancer risk comparative perception and overscreening behaviors of non-carriers from BRCA1/2 families. Manuscript submitted for publication.

National Cancer Institute (2008). Surveillance, Epidemiology, and End Results Program, “SEER" Stat Database: Incidence-SEER 17 Regs Public Use, Linked to County Attributes- Total US, 1969-2006 Counties. http://www.seer.cancer.gov/.

National Institute of Health (1997). Breast cancer screening for women ages 40-49. NIH Consensus Statement, 15, 1-35.

Nekolla, E. A., Griebel, J., \& Brix, G. (2008). Radiation risk associated with mammography screening examinations for women younger than 50 years of age. Zeitschrift für Medizinische Physik, 18(3), 170-179.

Nelson, H. D., Tyne, K., Naik, A., Bougatsos, C., Chan, B., Nygren, P., et al. (2009). Screening for Breast Cancer: Systematic Evidence Review Update for the US Preventive Services Task Force [Internet]. US Preventive Services Task Force Evidence Syntheses, Report No.: 10-05142-EF-1. 
O’Neill, S. C., Valdimarsdottir, H.B., DeMarco, T. A., Peshkin, B. N., Graves, K. D., Brown, K., et al. (2010). BRCA1/2 test results impact risk management attitudes, intentions and uptake. Breast Cancer Research and Treatment, 124(3), 755-764.

Perry, S. (2009). Breast self examination no longer recommended. Nursing New Zealand, 15(2), 12.

Peshkin, B. N., Schwartz, M. D., Isaacs, C., Hughes, C., Main, D., \& Lerman, C. (2002). Utilization of breast cancer screening in a clinically based sample of women after BRCA1/2 testing. Cancer Epidemiology, Biomarkers \& Prevention, 11, 1115-1118.

Pilarski, R. (2009). Risk perception among women at risk for hereditary breast and ovarian cancer. Journal of Genetic Counselling, 18, 303-312.

Pivot, X., Eisinger, F., Blay, J. Y., Coscas, Y., Calazel-Benque, A., Viguier, J., et al. (2011). Mammography utilization in women aged 40-49 years: the French EDIFICE survey. European Journal of Cancer Prevention, 20, suppl1, S16-19.

Qaseem, A., Snow, V., Sherif, K, Aronson, M., Weiss, KB. \& Owens, DK. (2007). Screening mammography for women 40 to 49 years of age: A clinical practice guideline from the American college of physicians. Annals of Internal Medicine, 146, 511-515.

Risch, H. A., McLaughlin, J. R., Cole, D.E., Rosen, B., Bradley, L., Kwan, E., et al. (2001). Prevalence and penetrance of germline BRCA1 and BRCA2 mutations in a population series of 649 women with ovarian cancer. American Journal of Human Genetics, 68(3), 700-710.

Risch, H. A., McLaughlin, J. R., Cole, D. E., Rosen, B., Bradley, L., Fan, I., et al. (2006). Population BRCA1 and BRCA2 mutation frequencies and cancer penetrances: a kincohort study in Ontario, Canada. Journal of National Cancer Institute, 98(23), 1694 1706.

Rogozinska-Szczepka, J., Utracka-Hutka, B., Grzybowska, E., Maka, B., Nowicka, E., SmokRagankiewicz, A., et al. (2004). BRCA1 and BRCA2 mutations as prognostic factors in bilateral breast cancer patients. Annals of Oncology, 15(9), 1373-1376.

Rosenstock, I. M. (1990). The health belief model: Explaining health behavior through expectancies. In K. Glanz, F. M. Lewis, \& B. K. Rimer (éd.), Health behavior and 
health education: Theory, research, and practice. (p. 39-62). San Francisco, CA US: Jossey-Bass.

Rosolowich, V. (2006). Breast self-examination. Journal of obstetrics and gynaecology Canada: 28(8), 728-730.

Rowe, J. L., Montgomery, G. H., Duberstein, P. R., \& Bovbjerg, D. H. (2005). Health locus of control and perceived risk for breast cancer in healthy women. Behavioral medicine, $31(1), 33-40$

Sabatino, S. A., McCarthy, E. P., Phillips, R. S., \& Burns, R. B. (2007). Breast cancer risk assessment and management in primary care: provider attitudes, practices, and barriers. Cancer Detection \& Prevention, 31(5), 375-383.

Salz, T., Richman, A.R., \& Brewer, N.T. (2010). Meta-analyses of the effect of false-positive mammograms on generic and specific psychosocial outcomes. Psychooncology $19,1026-1034$.

Smith, R. A. (2000). Breast cancer screening among women younger than age 50: a current assessment of the issues. Canadian Cancer Journal for Clinicians, 50(5), 312-336.

Tinley, S. T., Houfek, J., Watson, P., Wenzel, L., Clark, M. B., Coughlin, S., Lynch, H. T., et al. (2004). Screening adherence in BRCA1/2 families is associated with primary physicians' behavior. American Journal of Medical Genetics, 125A(1), 5-11.

US Preventive Services Task Force (2009). Screening for Breast Cancer: U.S. Preventive Services Task Force Recommendation Statement. Annals of Internal Medicine, 151(10), 716-726.

Vos, J., Oosterwijk, J.C., Gomez-Garcia, E., Menko, F.H., Colle, M.J., van Asperen, C.J. et al. (2012). Exploring the short-term impact of DNA-testing in breast cancer patients: The counselees' perception matters, but the actual BRCA1/2 result does not. Patient Education and Counseling, 86, 239-251.

Woloshin, S., Schwartz, L. M., Byram, S. J., Sox, H. C., Fischhoff, B., \& Welch, H. G. (2000). Women's understanding of the mammography screening debate. Archives of Internal Medicine, 160, 1434-1440. 
Yokoe, T., Iino, Y., Maemura, M., Takei, H., Horiguchi, J., Matsumoto, H., et al. (1998). Efficacy of mammography for detecting early breast cancer in women under 50 . Anticancer Research, 18(6B), 4709-4711. 
Table 1.

Overview of results of five studies in which over-screening practices of unaffected noncarrier women under age 50 were evaluated: percentages of uptake for the different (over)-screening practices, by age

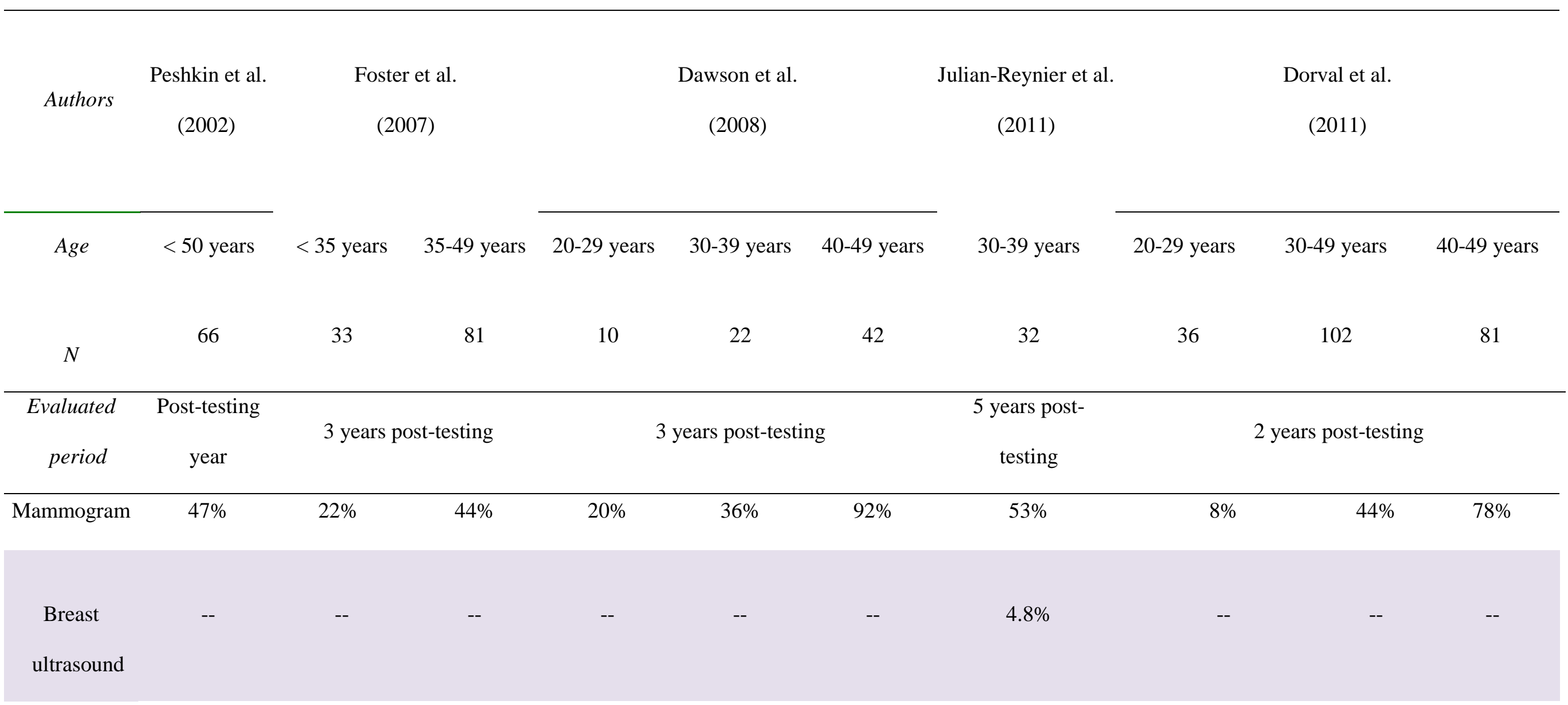




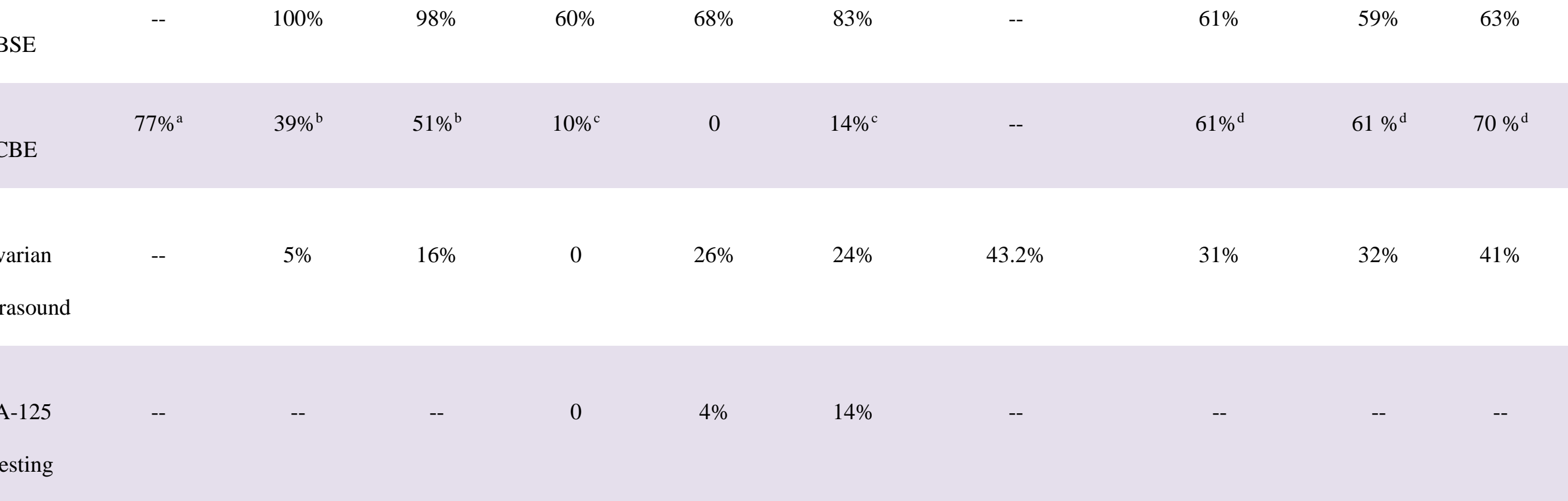

Note. $\mathrm{BSE}=$ breast self-examination; $\mathrm{CBE}=$ clinical breast examination;

apercentage of women who report having undertaken a clinical breast examination in the post-testing year;

bercentage of women who report at least one clinical breast examination in the 3 years post-testing;

c percentage of women who report having undertaken a clinical breast examination more than once a year in the 3 years post-testing;

${ }^{\mathrm{d}}$ percentage of women who report a clinical breast examination once a year in the 2 years post-testing 
Table 2.

Socio-demographic characteristics of participants

Unaffected noncarrier women

Under 40 years $(n=77) \quad 40$ to 49 years $(n=54)$

\begin{tabular}{lll}
\hline$n \%$ & $n$
\end{tabular}

\section{Educational level $^{a}$}

No qualifications

$2 \quad 2.6$

23.8

Diploma inferior to the baccalaureate

$4 \quad 5.2$

$14 \quad 26.9$

Diploma equivalent to the baccalaureate

$14 \quad 18.2$

$7 \quad 13.5$

(high school diploma)

Higher education diploma

$57 \quad 74.0$

$29 \quad 55.8$

\section{Socioprofessional category ${ }^{b}$}

Tradesmen, shopkeepers and business

owners

$\begin{array}{llll}4 & 5.2 & 4 & 7.5\end{array}$

Executives and senior intellectual

$16 \quad 20.8$

$8 \quad 15.1$

workers

Intermediate occupations

$16 \quad 20.8$

$13 \quad 24.5$

Administrative, Sales or Service

Occupations

$\begin{array}{llll}31 & 40.3 & 23 & 43.4\end{array}$

Manual labourers

$\begin{array}{llll}1 & 1.3 & 1 & 1.9\end{array}$

$\begin{array}{ll}9 & 11.7\end{array}$

$4 \quad 7.5$

No occupation

\section{Marital status}

$\begin{array}{lcccc}\text { Single } & 14 & 18.2 & 3 & 5.6 \\ \text { In a relationship } & 61 & 79.2 & 42 & 77.8 \\ \text { Divorcee } & 2 & 2.6 & 9 & 16.7 \\ & 53 & 68.8 & 50 & 92.6\end{array}$

Note.

${ }^{\text {a }}$ Two women aged 40-49 years did not indicate their educational level

${ }^{\mathrm{b}}$ One woman aged 40-49 years did not indicate her socioprofessional category 
Table 3.

Family history of the participants

\begin{tabular}{|c|c|c|c|c|}
\hline & \multicolumn{4}{|c|}{ Unaffected noncarrier women } \\
\hline & \multicolumn{2}{|c|}{ Under 40 years $(n=77)$} & \multicolumn{2}{|c|}{40 to 49 years $(n=54)$} \\
\hline & $n$ & $\%$ & $n$ & $\%$ \\
\hline $\begin{array}{l}\text { At least one first-degree relative affected by } \\
\text { breast and/or ovarian cancer }\end{array}$ & 53 & 68.8 & 34 & 62.9 \\
\hline $\begin{array}{l}\text { At least one first-degree relative deceased by } \\
\text { breast and/or ovarian cancer }\end{array}$ & 19 & 24.7 & 18 & 33.3 \\
\hline $\begin{array}{l}\text { At least another degree relative affected by } \\
\text { breast and/or ovarian cancer }\end{array}$ & 73 & 94.8 & 52 & 96.3 \\
\hline $\begin{array}{l}\text { At least another degree relative deceased by } \\
\text { breast and/or ovarian cancer }\end{array}$ & 65 & 84.4 & 45 & 83.3 \\
\hline $\begin{array}{l}\text { At least one relative affected by another type } \\
\text { of cancer }\end{array}$ & 66 & 85.7 & 47 & 87.0 \\
\hline $\begin{array}{l}\text { At least one relative deceased by another type } \\
\text { of cancer }\end{array}$ & 56 & 72.7 & 41 & 75.9 \\
\hline
\end{tabular}


Table 4.

Comparison of screening practices undertaken by unaffected noncarrier women under 40 to those of unaffected noncarrier women between 40 and 49

\begin{tabular}{lccccc} 
& \multicolumn{5}{c}{ Unaffected noncarrier women } \\
\cline { 2 - 6 } & \multicolumn{2}{c}{$\begin{array}{c}\text { Under } 40 \text { years } \\
(n=77)\end{array}$} & $\begin{array}{c}40 \text { to } 49 \text { years } \\
(n=54)\end{array}$ & $\chi^{2}(I)$ \\
\cline { 2 - 6 } & 18 & 23.4 & 45 & 83.3 & $45.71^{*}$ \\
Mammogram & 46 & 59.7 & 37 & 68.5 & 1.05 \\
Clinical breast examination & 33 & 42.9 & 27 & 50.0 & .65 \\
Breast self-examination & 15 & 19.5 & 28 & 51.8 & $15.08^{*}$ \\
Breast ultrasound & 19 & 24.7 & 12 & 22.2 & .10 \\
CA-125 testing & & & & & \\
& 0 & & 1 & & \\
\hline
\end{tabular}

Note. ${ }^{*} p<.001$ 


\section{Table 5.}

Frequency of uptake of screening practices for unaffected noncarrier women under 40 versus unaffected noncarrier women aged between 40 and 49 years

\begin{tabular}{|c|c|c|c|c|c|}
\hline \multirow{4}{*}{ Mammogram $^{a}$} & \multicolumn{4}{|c|}{ Unaffected noncarrier women } & \multirow{3}{*}{$\chi^{2}(1)$} \\
\hline & \multicolumn{2}{|c|}{$\begin{array}{c}\text { Under } 40 \text { years } \\
\quad(n=77)\end{array}$} & \multicolumn{2}{|c|}{$\begin{array}{c}40 \text { to } 49 \text { years } \\
(n=54)\end{array}$} & \\
\hline & $n$ & $\%$ & $n$ & $\%$ & \\
\hline & & & & & \\
\hline Less than once a year & 6 & 33.3 & 3 & 6.8 & - \\
\hline Once a year & 12 & 66.7 & 40 & 90.9 & $46.91 *$ \\
\hline Twice a year & $\mathbf{0}$ & 0 & 1 & 2.3 & - \\
\hline More often & $\mathbf{0}$ & $\boldsymbol{0}$ & 0 & 0 & - \\
\hline
\end{tabular}

\section{Clinical breast examination}

Less than once a year

Once a year

Twice a year

More often

\section{Breast self-examination ${ }^{b}$}

Less than once a year

Once a year

Twice a year

More often

\section{Breast ultrasound}

Less than once a year

Once a year

Twice a year
0

36

78.3

$\begin{array}{ll}9 & 19.6\end{array}$

1

2.2

0

15

12

4

12.9

48.4

38.7

$3 \quad 20$

2

$14 \quad 51.8$

$9 \quad 33.3$

$4 \quad 14.8$

0 0

$2 \quad 13.3$

$2 \quad 7.1$ 
More often

Ovarian ultrasound $^{c}$

Less than once a year

Once a year

Twice a year

More often
0

0

0

0
84.2

$\begin{array}{ll}2 & 10.5\end{array}$

1

16

5.3
0

0

\begin{tabular}{llll}
2 & 18.2 \\
\hline
\end{tabular}

Note. $* p<.001$; Sample sizes corresponding to over-screening practices are indicated in bold type.

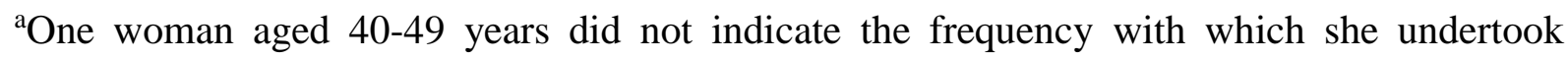
mammogram;

${ }^{\mathrm{b}}$ Two women under 40 did not indicate the frequency with which they undertook breast selfexamination;

${ }^{\mathrm{c}}$ One woman aged 40-49 years did not indicate the frequency with which she undertook ovarian ultrasound. 
Table 6.

Comparison of the motives for engaging in screening practices of unaffected noncarrier women under 40 versus unaffected noncarrier women aged between 40 and 49 years ${ }^{a}$

\begin{tabular}{ccc}
\hline \multicolumn{3}{c}{ Unaffected noncarrier women } \\
\cline { 1 - 2 } $\begin{array}{c}\text { Under 40 years } \\
(n=49)\end{array}$ & $\begin{array}{c}40 \text { to } 49 \text { years } \\
(\mathrm{n}=46)\end{array}$ & $\chi^{2}(I)$ \\
\hline$n \quad \%$ & $n \quad \%$ & \\
\hline
\end{tabular}

Motive

\begin{tabular}{lccccc}
\hline Early detection & 20 & 40.8 & 22 & 47.8 & .47 \\
Familial antedecents & 20 & 40.8 & 25 & 54.4 & 1.74 \\
Fear of cancer & 5 & 10.2 & 10 & 21.7 & 2.37 \\
Standard supervision & 5 & 10.2 & 3 & 6.5 & - \\
Age & 3 & 6.1 & 5 & 10.9 & - \\
Need for reassurance & 3 & 6.1 & 2 & 4.3 & - \\
For the child(ren) & 4 & 8.2 & 1 & 2.2 & - \\
Personal medical history (cysts) & 1 & 2.0 & 0 & & -
\end{tabular}

Note. ${ }^{\mathrm{a}} 11$ women under 40, and 5 women aged 40-49 years did not answer this question (missing data); some participants reported more than one motive for explaining their screening practices, hence the $n$ 's total > the sample sizes 
Table 7.

Comparison of the motives for increasing screening practices of unaffected noncarrier women under 40 versus unaffected noncarrier women aged $40-49$ years

Unaffected noncarrier women

\begin{tabular}{|c|c|}
\hline $\begin{array}{c}\text { Under } 40 \text { years } \\
\quad(n=22)\end{array}$ & $\begin{array}{c}40 \text { to } 49 \text { years } \\
(n=13)\end{array}$ \\
\hline$\%$ & $\%$ \\
\hline
\end{tabular}

Motive

\begin{tabular}{lcccc}
\hline $\begin{array}{l}\text { Increase of risks of cancer } \\
\text { when aging }\end{array}$ & 12 & 54.5 & 7 & 53.8 \\
Heredity & 1 & 4.5 & 1 & 7.7 \\
Prevention & 3 & 13.6 & 2 & 15.4 \\
Need for reassurance & 1 & 4.5 & 0 & \\
Standard supervision & 0 & & 2 & 15.4 \\
\hline
\end{tabular}

Note. Five women in the under 40 group and one woman in the 40 to 49 group did not answer this question 